\title{
Analysts' EPS Forecasts: The Effects of Forecast Uncertainty and Forecast Precision on Investors' Judgments of Forecast Reliability
}

\begin{abstract}
In this study, I use an experiment to investigate the joint effects of forecast precision and forecast uncertainty on investors' judgments of the reliability of analysts' EPS forecasts. Results indicate that participants' judgments of forecast reliability are not influenced by forecast uncertainty when precise analyst EPS forecasts are presented. In contrast, participants' judgments of forecast reliability are higher when forecast uncertainty is low than when it is high when round forecasts are presented. Further, I find that investors' judgments of the overall conditions under which the forecasts are made are influenced (not influenced) by forecast uncertainty, and that the relationship between forecast uncertainty and forecast reliability is mediated (not mediated) by investors' judgments of the overall conditions under which the forecasts are made when round (precise) forecasts are presented. My findings are informative to analysts and investors because it provides insights into how investors perceive and react to rounding in analysts' EPS forecasts under differing levels of earnings uncertainty.
\end{abstract}

Keywords: analyst forecast, earnings forecast, forecast uncertainty, rounding.

Data Availability: Please contact the author. 


\section{Analysts' EPS Forecasts: The Effects of Forecast Uncertainty and Forecast Precision on Investors' Judgments of Forecast Reliability}

\section{Introduction}

In issuing point earnings per share (EPS) forecasts, analysts can choose to issue round forecasts which end with the digits 0 or 5 or to issue precise forecasts which end with digits other than 0 or 5. Prior research has studied the frequency with which analysts issue round and precise EPS forecasts, and found that round EPS forecasts occur at a higher rate than should be expected (Herrmann and Thomas 2005). ${ }^{1}$ At the same time, prior research has also established that analysts' EPS forecasts are inherently associated with varying levels of uncertainty (e.g. Barron et al. 1998). In this study, I investigate how investors' judgments of analysts' EPS forecast reliability are jointly influenced by forecast uncertainty and forecast precision.

Investigating this issue is important. It is unclear how the level of precision in analysts’ EPS forecasts will influence investors' judgments of forecast reliability. On one hand, psychology research suggests that precise forecasts (relative to round forecasts) will lead to a positive attribution-of-competence effect (Loschelder et al. 2016) where precise forecasts positively influence perceptions of the personal characteristics of the analyst which subsequently form the basis of heuristic judgments of forecast reliability. Consistent with this, Dechow and You (2012) find that investors respond less to forecast errors made by analysts who issue round forecasts than to those who issue precise forecasts, suggesting that investors place less weight on the EPS forecasts made by analysts who issue round forecasts than those who issue precise forecasts. ${ }^{2}$ On the other hand, there is evidence that investors

\footnotetext{
${ }^{1}$ Prior studies have also examined rounding in various other settings (e.g. Roberts and Brewer 2001; Ureta 1992). The literature has classified this phenomenon as "heaping," which is often found in discrete quantitative data provided by subject reports or observer assessments.

${ }^{2}$ There is evidence that the attribution-of-competence effect can lead to accurate judgments of forecast reliability. For example, Hermann and Thomas (2005) find that round analyst EPS forecasts are often less accurate than precise analyst EPS
} 
also rely on round forecasts. In particular, Herrmann and Thomas (2005) find that, despite precise EPS forecasts being more accurate than round forecasts, both round and precise EPS forecasts issued by analysts are incorporated by investors in forming their earnings expectations of a target firm. One possible reason for the inconsistent insights provided by these prior studies is the fact that they do not examine contextual factors which may influence investor judgments in conjunction with forecast precision. In this regard, my study will complement these studies by examining the joint effects of forecast precision and one other contextual factor (forecast uncertainty) on investors' judgments of forecast reliability.

It is also important to examine the uncertainty associated with analysts' EPS forecasts. Prior studies suggest that the uncertainty in analysts' EPS forecasts provide important information about a firm's information environment prior to the release of accounting information (Sheng and Thevenot 2012). Because uncertainty is inherently unobservable, archival researchers have experimented with various proxies for earnings forecast uncertainty. One of the most commonly used measures of forecast uncertainty involves examining the dispersion among analysts' earnings forecasts (e.g. Yeung 2009; Clement et al. 2003). However, Johnson (2004) highlights that such measures of dispersion may not accurately measure analysts' earnings forecast uncertainty because we have no data on how confident any of the analysts is about his/her EPS forecasts. In theory, a group of analysts could agree on an EPS forecast while each being hugely uncertain. Conversely, they could also differ greatly from each other in their EPS forecasts while being enormously confident in their individual forecasts. To the extent that the proxies used in prior archival studies are unable to accurately measure analysts' earnings forecast uncertainty, my study

forecasts, and that analysts who issue round EPS forecasts are more likely to display characteristics of less informed, lower effort analysts than those who issue precise EPS forecasts. 
complements these studies by using an experiment to examine investor reactions to clean manipulations of high and low uncertainty in analysts' EPS forecasts.

I draw on the heuristic-systematic model (HSM) to develop my theory. In particular, the sufficiency principle of the HSM (Chaiken 1980; 1987) suggests that heuristic processing is the default (initial) processing strategy that people rely on in forming judgments, and that more effortful systematic processing occurs only when heuristic processing alone yields insufficient judgment confidence to breach their sufficiency thresholds (Bohner et al. 1995). In my study, investors are expected to initially rely on heuristic processing in forming reliability judgments. When precise EPS forecasts are presented, investors will interpret the forecasts as positive signals of analysts' personal characteristics (a positive attribution-ofcompetence effect). These positive signals of the analysts' personal characteristics will in turn represent heuristic cues on which investors' judgments of forecast reliability will be based. To the extent that these positive signals of the analysts' personal characteristics provide investors with a sufficiently high sense of judgment confidence to satisfy their sufficiency thresholds, these heuristic processes will form the basis of their judgments of forecast reliability. Investors will not engage in systematic processing, and other contextual factors such as forecast uncertainty will not influence their judgments of forecast reliability. Accordingly, I predict that when precise EPS forecasts are provided, investor judgments of forecast reliability will not be influenced by forecast uncertainty. I also predict that when precise forecasts are presented, investors' judgments of the overall conditions under which the forecasts were made will not be influenced by forecast uncertainty, and that the relationship between forecast uncertainty and investors' judgments of forecast reliability will not be mediated by these judgments of the overall conditions under which the forecasts were made. While precise forecasts are expected to send positive signals of the analysts' personal characteristics to investors, round forecasts are not expected to send equivalent negative 
signals of their personal characteristics. ${ }^{3}$ To the extent that round EPS forecasts do not lead to a significant negative attribution-of-competence effect, heuristic processing is unlikely to provide investors with a sufficiently high sense of confidence in their judgments of forecast reliability to satisfy their sufficiency thresholds. Investors are then expected to further engage in systematic processes, carefully processing all relevant information, including contextual factors such as forecast uncertainty (Hermann and Thomas 2005), when forming their forecast reliability judgments. Accordingly, I predict that when round EPS forecasts are provided, investor judgments of forecast reliability will be negatively influenced by forecast uncertainty. I also predict that when round forecasts are presented, investors' judgments of the overall conditions under which the forecasts were made will be negatively influenced by forecast uncertainty, and that the relationship between forecast uncertainty and investors' judgments of forecast reliability will be mediated by their judgments of the overall conditions under which the forecasts were made.

I examine these issues using an experiment which allows me to manipulate the level of forecast precision in analysts' EPS forecasts while keeping all other information communicated by the analyst constant (other financial information, qualitative reasons provided in support of forecasts, etc). This is important given that such peripheral information communicated by analysts can also influence investor judgments of forecast reliability. An experiment also allows me to investigate the specific mechanisms through which forecast precision and forecast uncertainty influence investor judgments of forecast reliability, which would be almost impossible to do archivally. To examine my research question, I conducted a 2 (round versus precise) x 2 (high_uncertainty versus low_uncertainty) between-subjects experiment using participants recruited on Amazon's Mechanical Turk (AMT) platform as proxies for non-professional investors. I manipulated

\footnotetext{
${ }^{3}$ See page 11 for a discussion of the non-symmetrical nature of positive and negative attribution-of-competence effects.
} 
forecast precision by providing participants with an analyst report containing EPS forecasts of $\$ 10.00$ ( $\$ 10.11)$ in the round (precise) condition. I manipulated forecast uncertainty by providing participants in the high_uncertainty (low_uncertainty) condition with an analyst report which highlights that the certainty associated with the EPS forecast provided is low (high) because the certainty associated with the timing of future cash flows from a major contract is low (high). After attending to the analyst report, participants answered questions related to their judgements about the target company as an investment, the reliability of the analysts' EPS forecasts, and other characteristics of the forecasts and the analysts. They also answered questions relating to manipulation checks, attention checks, and demographic information.

Results indicate that participants' judgments of forecast reliability were no different across forecast uncertainty conditions when analysts' EPS forecasts were precise. In contrast, their judgments of forecast reliability were higher in the low_uncertainty condition than in the higher_uncertainty condition when analysts EPS forecasts were round. In addition, participants' judgments of the overall conditions under which the forecasts were made were no different across forecast uncertainty conditions when analysts' EPS forecasts were precise. However, their judgments of the overall conditions under which the forecasts were made were higher in the low_uncertainty condition than in the high_uncertainty condition when analysts EPS forecasts were round. I also find that the effects of forecast uncertainty on judgments of forecast reliability were mediated by participants' judgments of the overall conditions under which the forecasts were made in the round condition but not in the precise condition. I conduct additional analysis in two areas. First, I examine the relationship between participants' judgments of forecast reliability and their investment judgments. I find that their judgments of forecast reliability were significantly associated with their investment judgments, suggesting that judgments of forecast reliability influence subsequent investment 
judgments. Second, I investigate the possibility that the results in my main experiment were driven by differences in the magnitudes of the EPS forecasts provided across forecast precision conditions rather than by differences in forecast precision. Two additional experimental conditions (precise_small/low_uncertainty and precise_small/high uncertainty) were administered at the same time as the other conditions in the main experiment. All aspects of the precise_small/low_uncertainty and precise_small/high_uncertainty/conditions were identical to the precise/low_uncertainty and precise/high_uncertainty conditions (respectively), except that analyst EPS forecasts of \$9.89 (rather than \$10.11) were provided in the two new conditions. This ensures that while the EPS forecasts provided in the precise condition is $\$ 0.11$ larger than those provided in the round condition, the EPS forecasts provided in the precise_small condition is $\$ 0.11$ smaller than that provided in the round condition. I find that participants' judgments of forecast reliability in the precise_small condition were no different from in the precise conditions across forecast uncertainty conditions, suggesting that my results in the main experiment are not driven by differences in forecast magnitude.

My findings contribute to academic research and to practice. My study is the first to examine the joint effects of forecast precision and forecast uncertainty on investor judgments of the reliability of analysts' EPS forecasts. My findings are informative to analysts and investors because they provide insights into how investors perceive and react to differing levels of forecast precision under differing levels of forecast uncertainty. My study also extends the existing research on the phenomenon of rounding in analysts EPS forecasts. Prior studies focus on examining the characteristics of analysts who are more likely to issue round than precise EPS forecasts (Herman and Thomas 2005) and on the reasons that analysts choose to issue round (versus precise) EPS forecasts (Dechow and You 2012). By examining how investors' forecast reliability judgments are influenced by the issuance of round versus 
precise EPS forecasts by analysts, my study complements these prior studies by providing insights into how investors, who are one important group of users of analyst EPS forecasts, interpret and rely on round and precise analyst EPS forecasts. In this regard, my study answers the call by Herrmann and Thomas (2005) to investigate the extent to which the decisions of users of analyst EPS forecasts are affected by the phenomenon of rounding by analysts. In addition, my study complements the existing research examining how forecast precision influences investor judgments. Rupar (2017) investigates whether the alignment between individual investors' expectations about managers' EPS forecast precision (operationalized as range versus point forecasts) and actual forecast precision influence their judgments. She finds that investor judgments are more positive when expected and actual forecast precision align than when they do not align. My study differs from and complements Rupar (2017) in three key ways. First, Rupar (2017) varies forecast precision by providing participants in her experiment with either point or range EPS forecasts. In contrast, I vary forecast precision by providing my participants with point EPS forecasts which either end with two precise digits $(\$ 10.11)$ or with two round digits $(\$ 10.00)$. In this regard, my study complements Rupar (2017) and answers the call by Bamber et al. (2010) for research to refine traditional categories of forecasting rather than categorizing all point forecasts as if they were equally precise. I do so by highlighting how the precision in EPS forecasts can vary by the number of precise digits that point forecasts end with. Second, Rupar (2017) examines the alignment between participants' expectations about forecast precision and actual forecast precision by first introducing contextual information about environmental uncertainty followed by information about forecast precision. In her experiment setting, it is likely that the sequential presentation of information served to first create an expectation in participants about what constituted a suitable level of forecast precision (using environmental uncertainty) before revealing the actual forecast to them. In contrast, I provide both 
contextual information about forecast uncertainty and about forecast precision to participants at the same time, in the form of an analyst report. My results (particularly that forecast uncertainty does not influence investor judgments of forecast reliability when EPS forecasts are round) complements Rupar (2017) and highlights a scenario where uncertainty surrounding a forecast does not necessarily lead to expectations about what level of precision a corresponding EPS forecast should take on. It also suggests that the sequence by which investors receive information can influence how they process that information. Understanding how differences in the sequence by which information is presented can influence investor judgments is important given that prior studies have found that investors engage in a variety of different information search strategies when making investment decision and may not receive information in the same sequence (Loibl and Hira 2009). Third, Rupar (2017) provides management EPS forecasts to participants. In addition, she also explicitly discusses the motivation for managers to undershoot actual EPS in their forecasts (which is likely to generate expectations about subsequent forecast precision). In contrast, I provide analyst EPS forecasts to participants. To the extent that managers and analysts have different motivations in providing earnings forecasts (Mittendorf and Zhang 2005), my study complements Rupar (2017) by highlighting differences between how investors react to EPS forecasts provided by analysts and managers. My study also extends the existing research on information uncertainty. Prior studies have examined how information uncertainty can influence investors. ${ }^{4}$ For example, Zhang (2006) finds that investors tend to underreact more to new information when there is more ambiguity with respect to its implication for firm value. By investigating how forecast uncertainty influences investor judgments of forecast reliability, my study highlights how forecast uncertainty, which can contribute to ambiguity with respect to the implications of analysts' EPS forecasts for the expected earnings of a

\footnotetext{
${ }^{4}$ Zhang (2006) refers to information uncertainty as ambiguity with respect to the implications of new information for a firm's value
} 
target firm, influences investor judgments of forecast reliability when forecasts are round but not when they are precise.

The rest of my study proceeds as follows. Section 2 highlights my theory and develops my hypotheses. Section 3 reports the method that I use to test the hypotheses. Section 4 presents the results of my experiment and section 5 presents my additional analyses. Finally, section 6 concludes the study.

\section{Theory and hypothesis development}

I draw on the heuristic-systematic model (HSM; Chaiken 1980, 1987) to develop my theory. The HSM suggests that people engage in two broad information processing strategies, situated at either end of a continuum, in forming judgments. On one end of the continuum, heuristic processing dominates. Heuristic processing is a limited mode of information processing that requires little cognitive effort and resources, and involves the use of judgmental rules or heuristics. Judgments formed on the basis of heuristic processes reflect easily processed heuristic cue information rather than individualistic or particularistic information (Chen et al. 1999). On the opposite end of the continuum, systematic processing dominates. Systematic processing involves effortful and deliberate processing. In processing information systematically, people comprehensively evaluate and integrate relevant information in forming their judgments (Bohner et al. 1995). While heuristic and systematic modes of processing may occur independently, they may also co-occur, either in an additive fashion (Maheswaran and Chaiken 1991) or in a way where the judgmental implications of one mode bias the nature of the other (Chaiken and Maheswaran 1994). The HSM's sufficiency principle contends that people attempt to strike a balance between minimizing cognitive effort and maximizing confidence in their judgements (Chaiken et al. 1989; Chaiken et al.1996). In this regard, the sufficiency principle establishes a sufficiency 
threshold which represents the point at which people feel sufficiently confident in their judgments to rely on them. In forming judgments, people will exert more effort and continue working on the judgment task until the sufficiency threshold is reached or surpassed. The sufficiency principle further suggests that heuristic processing is the default (initial) processing strategy in forming judgments, and that more effortful systematic processing occurs only when heuristic processing alone yields insufficient judgment confidence to breach the sufficiency threshold (Bohner et al. 1995). ${ }^{5}$

Prior research suggests that the expression of precision in forecasts can positively influence perceptions of the personal characteristics of the forecaster (knowledge, competence, confidence, etc), and that these perceptions of the forecaster's personal characteristics can form the basis of subsequent heuristic judgments (Hayward and Fitza 2017). Loschelder et al. (2016) term this phenomenon the attribution-of-competence effect. Consistent with the attribution-of-competence effect, Mason et al. (2013) find that in the negotiation context, precise (versus round) offers signal a greater level of knowledge and are assumed by recipients to be more informative of the value of the good being negotiated. Further, Jerez-Fernandez et al. (2014) find that people judged providers of precise (versus round) estimates as being more confident in their estimates and subsequently relied more heavily on such estimates. In the accounting setting, Hayward and Fitza (2017) find that managements' earnings forecast precision has a direct positive effect on a firm's share price movement on the day the forecast is announced and suggest that this is indicative of the market valuing the higher sense of control that managers are projecting by providing more precise earnings guidance.

\footnotetext{
${ }^{5}$ This assumption is consistent with the least effort principle, which is a related principle provided by the HSM. It assumes that people are economy-minded processors who only expend cognitive resources when they are truly required (Bohner et al., 1995).
} 
In my study, investors are, in accordance with the HSM, expected to initially rely on heuristic processes in forming judgments about the reliability of analysts' EPS forecasts. When precise EPS forecasts are provided, they will interpret the precise forecasts as positive signals of the analysts' personal characteristics. These positive signals of the analysts' personal characteristics will in turn represent heuristic cues on which investors' judgments of forecast reliability will be based (i.e. a positive attribution-of-competence effect). To the extent that these positive signals of the analysts' personal characteristics provide investors with a sufficiently high sense of confidence to satisfy the sufficiency threshold, these heuristic processes will form the basis of their judgments of forecast reliability. Investors are not expected to engage in any further systematic processing of information when precise forecasts are presented. Accordingly, contextual information such as forecast uncertainty will not influence their judgments of forecast reliability. This leads to $\mathrm{H} 1$ :

H1: When analysts issue precise EPS forecasts, investors' judgments of forecast reliability will be no different when forecast uncertainty is low and when it is high.

While precise forecasts are expected to send positive signals of the analysts' personal characteristics to investors, round forecasts are not expected to send equivalent negative signals of their personal characteristics (i.e. the positive and negative signals are not symmetric). In particular, Loschelder et al. (2016) suggest that the attribution-of-competence effect will be accentuated (diminished) when the level of precision provided in a forecast is inconsistent (consistent) with the perceived norm. Accordingly, in the context of analyst EPS forecasting where round forecasts are the norm in that they are both more prevalent than precise forecasts and occur at rates that are much greater than expected (Herrmann and Thomas 2005), the provision of a precise EPS forecast will distinguish an analyst from his/her peers and result in a positive attribution-of-competence effect. In contrast, the provision of a round EPS forecast will not significantly distinguish an analyst from his/her 
peers and will not result in a significant negative attribution-of-competence effect. To the extent that round EPS forecasts do not lead to a significant negative attribution-ofcompetence effect, heuristic processing is unlikely to provide investors with a sufficiently high sense of confidence in their judgments of forecast reliability to satisfy the sufficiency threshold (as it did when precise forecasts were provided). In accordance with the sufficiency principle, investors are then expected to further engage in systematic processes, carefully processing all relevant information, including contextual factors such as forecast uncertainty which can reduce the perceived reliability of analyst forecasts (Hermann and Thomas, 2005), in making their forecast reliability judgments. This leads to $\mathrm{H} 2$ :

H2: When analysts issue round EPS forecasts, investors' judgments of forecast reliability will be more positive when forecast uncertainty is low than when it is high.

Figure 1 provides a graphical depiction of my predictions of investors' judgments of forecast reliability. The line representing the effects of forecast uncertainty on investors' judgments of forecast reliability when EPS forecasts are precise is flat while the line representing the effects of forecast uncertainty on investors' judgments of forecast reliability when EPS forecasts are round is a slope, reflecting my predictions in $\mathrm{H} 1$ and $\mathrm{H} 2$. Figure 1 shows a difference in forecast reliability judgments for round forecasts and for precise forecasts when forecast uncertainty is high, reflecting the positive attribution-of competence effect when forecasts are precise and the negative effect that high forecast uncertainty is expected to have on forecast reliability when systematically processing this information when forecasts are round. In contrast, figure 1 shows no such difference in judgments for round and precise forecasts when forecast uncertainty is low, reflecting the positive attribution-of competence effect when forecasts are precise and the positive effect that low forecast uncertainty is expected to have on forecast reliability when systematically processing this information when forecasts are round. Overall, this suggests that an ordinal interaction (i.e. 
non-symmetric pattern of cell means) will be observed when examining the effects of $\mathrm{H} 1$ and H2 (Buckless and Ravenscroft 1990).

\section{(Insert Figure 1 here)}

$\mathrm{H} 1$ predicts that when analysts issue precise EPS forecasts, the effects of heuristic processes will dominate, with investors' forecast reliability judgments being based on a positive attribution-of-competence effect derived from analysts' precise EPS forecasts. To the extent that forecast uncertainty does not influences heuristic processing, it is not expected to influence participants' overall judgments of the conditions under which analysts' EPS forecasts were made. These overall judgements are also not expected explain the relationship between forecast uncertainty and investors' judgments of forecast reliability. This leads to $\mathrm{H} 3 \mathrm{a}$ and $\mathrm{H} 3 \mathrm{~b}$ :

H3a: When analysts issue precise EPS forecasts, investors' overall judgments of the conditions under which analysts' EPS forecasts were made will be no different when forecast uncertainty is low and when it is high.

H3b: When analysts issue precise EPS forecasts, the relationship between forecast uncertainty and investors' judgments of forecast reliability will not be mediated by their overall judgments of the conditions under which analysts' EPS forecasts were made.

$\mathrm{H} 2$ predicts that when analysts issue round EPS forecasts, heuristic processes will not provide investors with a sufficiently high sense of confidence in their judgments of forecast reliability to satisfy their sufficiency thresholds. Consequently, investors will then engage in systematic processing, carefully processing all relevant information, including contextual factors such as forecast uncertainty. To the extent that, in systematically processing information, investors evaluate all relevant information, forecast uncertainty is expected to influence their overall judgments of the conditions under which analysts' EPS forecasts were 
made. These overall judgements are also expected to explain the relationship between forecast uncertainty and investors' judgments of forecast reliability. This leads to H4a and H4b:

H4a: When analysts issue round EPS forecasts, investors' overall judgments of the conditions under which analysts' EPS forecasts were made will be more positive when forecast uncertainty is low than when it is high.

H4b: When analysts issue round EPS forecasts, the relationship between forecast uncertainty and investors' judgments of forecast reliability will be mediated by their overall judgments of the conditions under which analysts' EPS forecasts were made.

\section{Method}

\subsection{Participants}

I conducted an experiment with 123 participants recruited from Amazon's Mechanical Turk (AMT) platform. This pool of participants represents suitable proxies for nonprofessional investors. In particular, AMT has been used in prior research that study nonprofessional investors (e.g. Koonce et al. 2015; Rennekamp 2012), and has been demonstrated to replicate results obtained in existing accounting studies (Krische 2015). The literature shows that participants recruited on the AMT platform exert just as much effort as other student participants commonly used in such studies (Paolacci et al. 2010). Recruiting from the AMT platform allows me to use participants who possess sufficient knowledge to perform the experiment but at the same time do not represent subjects who are more sophisticated than necessary (Libby et al. 2002). Hauser and Schwarz (2016) suggest that including attention check questions in experimental studies using AMT subjects are an effective way to determine if participants pay sufficient attention when completing experiments. I include two attention check questions in my experiment. Overall, $89.4 \%$ 
$\left(\chi^{2}=76.50, p<0.01\right)$ of participants answered the first attention check question correctly and $79.7 \%\left(\chi^{2}=43.33, \mathrm{p}<0.01\right)$ of participants answered the second attention check question correctly, at rates that are greater than chance. To ensure that my analysis includes participants who paid sufficient attention to the experimental material, I excluded 31 participants who answered at least one attention check question incorrectly, leaving a total of 92 participants in my analysis. ${ }^{6}$ These 92 participants had a mean (standard deviation) age of 31.30 (6.81) years, a mean (standard deviation) work experience of $6.66(6.63)$ years, and had taken a mean (standard deviation) of 1.95 (2.47) accounting/finance courses. About $71.70 \%$ of them had investment experience and $71.70 \%$ of them intended to make investments in the next twelve months.

\subsection{Design and procedure}

I used a 2 (low_uncertainty versus high_uncertainty) x 2 (round versus precise) between-participants experiment design to test my hypotheses. Participants were randomly assigned to one of four online experimental conditions administered via Qualtrics. They were told to assume the role of a shareholder assessing the earnings prospects of GR Ocean, a fictitious company. Participants were then provided with background information about GR Ocean consisting of an introduction to the firm and a summary of its most recent quarterly financial results. Next, participants were told that they would view an analyst report on GR Ocean produced by an independent equities research firm. Participants in the low_uncertainty condition were given an analyst report which highlighted that there was a high level of certainty in its EPS forecast along with a statement indicating that "The certainty of our EPS forecast is high because GR Ocean was able to provide details about the timing of the

\footnotetext{
${ }^{6}$ Participants' judgments of the reliability of analysts' EPS forecasts are similar when I include all 123 participants in my analysis. Inferences for the conventional ANOVA test, planned contrast test, and simple effects tests presented in Table 1 are identical when all 123 participants are included. I note that excluding these 31 participants from my analysis biases against my finding support for $\mathrm{H} 1, \mathrm{H} 3 \mathrm{a}$, and $\mathrm{H} 3 \mathrm{~b}$ which posit that participants in the precise condition form judgments using heuristic processing. Two-tailed tests are presented here and elsewhere in the paper unless otherwise specified.
} 
execution of the contract in its most recent earnings call." Participants in the high_uncertainty condition were given an analyst report which highlighted that there was a low level of certainty in its EPS forecast along with a statement indicating that "The certainty of our EPS forecast is low because GR Ocean was not able to provide details about the timing of the execution of the contract in its most recent earnings call." ${ }^{7}$ Further, participants in the round (precise) condition were given an analyst report which stated that the analysts' EPS forecast for GR Ocean was $\$ 10.00$ (\$10.11) for the upcoming financial year. Consistent with prior studies (e.g. Janiszewski and Uy 2008), I manipulate forecast precision by varying the number of precise digits (i.e. numbers other than 0 or 5) that an EPS forecast ends with.

Following that, participants answered questions relating to their investment decisions. Specifically, they provided their estimates of the company's maximum and minimum EPS for the upcoming financial year. They also rated the extent to which they agreed that the company was a good investment. Next, participants rated the extent to which they agreed that the EPS forecast was reliable and that the analysts who wrote the report were informed about the company, had put in effort to research and write the report, and had sufficient information to provide the forecast. These ratings were made on a fifteen-point scale with 0 as the midpoint and -7 (+7) corresponding to "strongly disagree" (“strongly agree”). Finally, participants answered questions on attention checks, manipulation checks, and demographic information.

\section{Results}

\footnotetext{
${ }^{7}$ There is evidence that analysts specifically discuss the uncertainty associated with their earnings forecasts. For example, an analyst report published by J.P. Morgan on insurance company Tokio Marine (Tsujino 2012) states that "the certainty of our 1H earnings estimates is low." Further, another analyst report by J. P. Morgan on American Electric Power (Smith et al. 2012) attributes the uncertainty in its earnings forecast to the Public Utilities Commission of Ohio's announcement that it was "revoking its previous settlement decision regarding AEP's Energy Security Plan (ESP)." The report further states that the analysts "believe this decision could have a material impact to AEP's earnings outlook, but we also believe it is too early to estimate the impact due the uncertainty of the outcome." Consistent with the accounting literature (e.g. Sheng and Thevenot 2012) I refer to this construct as forecast uncertainty in my paper. However, I note that analysts routinely refer to the certainty (rather than uncertainty) associated with their forecasts (e.g. Tsujino 2012; Smith et al. 2012). Accordingly, I operationalize forecast uncertainty in my experiment by referring to the certainty (rather than uncertainty) associated with earnings forecast. Analyst reports used in the experiment are provided in Appendix 1.
} 
4.1. Manipulation checks

Approximately $66.67 \%$ of participants were able to correctly identify whether they were provided with EPS forecasts that were precise or round, at a rate that is greater than chance $\left(\chi^{2}=13.67, \mathrm{p}<0.01\right)$. Hence, the manipulation of analyst forecast precision was successful. Also, participants' ratings of the level of certainty associated with the analysts' EPS forecast was significantly higher in the low_uncertainty condition (mean=4.61) than in the high_uncertainty condition (mean $=0.76, \mathrm{t}=6.07, \mathrm{p}<0.01$ ). The manipulation of forecast uncertainty was successful. $^{8}$

\subsection{Judgments of forecast reliability ( $\mathrm{H} 1$ and $\mathrm{H} 2)$}

H1 states that when an analyst issues precise EPS forecasts, investors' judgments of forecast reliability will not be influenced by forecast uncertainty while $\mathrm{H} 2$ states that when an analyst issues round EPS forecasts, investors' judgments of forecast reliability will be more positive when forecast uncertainty is low than when it is high. Panel A of Table 1 presents descriptive statistics for reliability, which represents participants' ratings of their agreement that the analysts' EPS forecast was reliable. ${ }^{9}$ Consistent with $\mathrm{H} 1$, I find that reliability is no different in the low_uncertainty/precise (mean=3.23) and high_uncertainty/precise (mean $=2.83, \mathrm{t}=0.49, \mathrm{p}=0.63$ ) conditions. Consistent with $\mathrm{H} 2$, I find that reliability is significantly higher in the low_uncertainty/round condition (mean=3.58) than in the high_uncertainty/round condition (mean $=1.52, \mathrm{t}=2.78, \mathrm{p}=0.01)$. Further, I find that reliability is no different between the low_uncertainty/round (mean $=3.58, \mathrm{t}=0.49, \mathrm{p}=0.63$ ) and low_uncertainty/precise $($ mean $=3.23)$ conditions, and no different between the high_uncertainty/round $($ mean $=1.52, \mathrm{t}=1.57, \mathrm{p}=0.12)$ and high_uncertainty/precise

\footnotetext{
${ }^{8}$ Participants made their judgments on a fifteen-point scale, with 0 as the midpoint and $-7(+7)$ corresponding to "high level of certainty" ("low level of certainty").

${ }^{9}$ Ratings were made on a fifteen-point scale, with 0 as the midpoint and $-7(+7)$ corresponding to "strongly disagree" ("strongly agree").
} 
(mean=2.83) conditions. The conventional analysis of variance (ANOVA) presented in panel B shows a significant main effect of forecast uncertainty on reliability $(\mathrm{F}=4.97, \mathrm{t}=0.03)$ and an insignificant main effect of forecast precision on reliability $(\mathrm{F}=0.74, \mathrm{p}=0.39)$. It also shows an insignificant interaction effect of forecast uncertainty and forecast precision on reliability $(\mathrm{F}=2.26, \mathrm{t}=0.14)$. However, because I predict an ordinal interaction, contrast coding is the most appropriate and powerful means of testing $\mathrm{H} 1$ and $\mathrm{H} 2$ (Buckless and Ravenscroft 1990). As shown in Panel C, the planned contrast is statistically significant $(\mathrm{F}=7.03, \mathrm{t}=0.01)$, consistent with the effects predicted in $\mathrm{H} 1$ and $\mathrm{H} 2 .{ }^{10}$ Follow up simple effects tests in Panel D show that the effects of forecast uncertainty on reliability are not significant when forecasts are precise $(\mathrm{F}=0.24, \mathrm{t}=0.63)$ but are significant when forecasts are round $(\mathrm{F}=7.70, \mathrm{t}=0.01)$. Overall, these results are consistent with $\mathrm{H} 1$ and $\mathrm{H} 2$.

\section{(Insert Table 1 here)}

\subsection{Overall judgments of forecast characteristics ( $\mathrm{H} 3 \mathrm{a}$ and $\mathrm{H} 4 \mathrm{a})$}

The experiment asked two questions which required participants to make judgements about their agreement that the analysts who wrote the analyst report are informed about the company and had sufficient information to provide the EPS forecast. These questions were designed to capture participants' overall judgments of the conditions under which analysts' EPS forecasts were made. To examine the underlying construct for these judgements, I conducted a factor analysis of these two judgements for all participants. The factor analysis reveals that the judgments load onto a single factor which explains $85.06 \%$ of the variance in participants' responses. ${ }^{11}$ A reliability analysis also reveals a high Cronbach's alpha of 0.82 , suggesting that the factor measures the underlying construct with a high level of consistency.

\footnotetext{
${ }^{10}$ Contrast codes are +1 in the two precise conditions, +1 in the low_uncertainty/round condition, and -3 in the high_uncertainty/round condition.

${ }^{11}$ Participants made their judgements of these two questions on fifteen-point scales with 0 as the midpoint and $-7(+7)$ corresponding to "strongly disagree" ("strongly agree"). Factor analysis was conducted using the principal components extraction method.
} 
Accordingly, I calculated participants' average judgments of these two questions to obtain a composite measure of their overall judgments of the conditions under which analysts' EPS forecasts were made (judge_forecast).

H3a predicts that when analysts issue precise EPS forecasts, investors' overall judgments of the conditions under which analysts' EPS forecasts were made will be no different when forecast uncertainty is low and when it is high. H4a predicts that when analysts issue round EPS forecasts, investors' overall judgments of the conditions under which analysts' EPS forecasts were made will be more positive when forecast uncertainty is low than when it is high. Panel A of Table 2 presents descriptive statistics for participants' ratings of judge_forecast. I find that judge_forecast is no different in the low_uncertainty/precise condition (mean=3.84) and the high_uncertainty/precise condition (mean $=3.20, \mathrm{t}=1.08, \mathrm{p}=0.29)$. Judge_forecast is higher in the low_uncertainty/round condition (mean=3.83) than in the high_uncertainty/round condition (mean=1.50, $\mathrm{t}=3.44$, $\mathrm{p}<0.01) .{ }^{12}$ Follow up tests in panel B show that the effects of forecast uncertainty on judge_forecast are significant when forecasts are round $(\mathrm{F}=11.80, \mathrm{t}<0.01)$ but not significant when forecasts are precise $(\mathrm{F}=4.68, \mathrm{t}=0.29)$. Overall, these results are consistent with $\mathrm{H} 3 \mathrm{a}$ and $\mathrm{H} 4 \mathrm{a}$.

\section{(Insert Table 2 here)}

\subsection{Mediation effects of judge_forecast ( $\mathrm{H} 3 \mathrm{~b}$ and $\mathrm{H} 4 \mathrm{~b})$}

$\mathrm{H} 3 \mathrm{~b}$ predicts that when analysts issue precise EPS forecasts, the relationship between forecast uncertainty and investors' judgments of forecast reliability (reliability) will not be mediated by their overall judgments of the conditions under which analysts' EPS forecasts

\footnotetext{
12 Judge_forecast in the low_uncertainty/round condition $(m e a n=3.83)$ is no different from in the low_uncertainty/precise condition (mean $=3.84, \mathrm{t}=0.01, \mathrm{p}=0.99$ ). It is significantly higher in the high_uncertainty/precise condition $(\mathrm{mean}=3.20)$ than in the high_uncertainty/round condition (mean $=1.50, \mathrm{t}=2.41, \mathrm{p}=0.02)$.
} 
were made (judge_forecast). In contrast, $\mathrm{H} 4 \mathrm{~b}$ predicts that when analysts issue round EPS forecasts, the relationship between forecast uncertainty and investors' judgments of forecast reliability (reliability) will be mediated by overall judgments of the conditions under which analysts' EPS forecasts were made (judge_forecast). Following the bias-corrected bootstrapping method (Hayes 2012; Preacher and Hayes 2008), I use the mediation model (model 4) in the Hayes PROCESS macro to estimate the path coefficients through 10,000 bootstrapped samples with a $90 \%$ confidence interval to investigate $\mathrm{H} 3 \mathrm{~b}$ and $\mathrm{H} 4 \mathrm{~b}$.

Figure 2 presents the graphical depiction and results of the mediation model in the precise condition $(\mathrm{H} 3 \mathrm{~b})$. The effect of forecast uncertainty on judge_forecast is not significant (coefficient $=-0.65, \mathrm{p}=0.29$ ). The effect of judge_forecast on reliability is positive (coefficient $=0.97, \mathrm{p}<0.01$ ). At the same time, the direct effect of forecast uncertainty on reliability is insignificant (coefficient $=0.23, \mathrm{p}=0.71$ ). Overall, there is an insignificant indirect effect of forecast uncertainty on reliability via judge_forecast, with the $90 \%$ confidence interval $(\mathrm{CI})$ including zero (effect $=-0.63,90 \% \mathrm{CI}$ : -1.63 to 0.28 ). These results suggest that the effect of forecast uncertainty on reliability is not mediated by judge_forecast, consistent with $\mathrm{H} 3 \mathrm{~b}{ }^{13}$

\section{(Insert Figure 2 here)}

Figure 3 presents the graphical depiction and results of the mediation model in the round condition $(\mathrm{H} 4 \mathrm{~b})$. There is a negative effect of forecast uncertainty on judge_forecast

\footnotetext{
${ }^{13}$ My theory suggests that in relying on heuristic processing, participants in the precise condition will rely on their judgments of the personal characteristics of the analysts as a heuristic cue in forming their judgments of EPS forecast reliability. In my experiment, participants rated their agreement that the analysts had put in effort in making the EPS forecasts (analyst_effort) on a fifteen-point scale with 0 as the midpoint and -7 (+7) corresponding to "strongly disagree" ("strongly agree"). Prior research suggests one key analyst personal characteristic in making EPS forecasts is the amount of effort that they expand in making the forecasts (e.g. Dechow and You, 2012; Herrmann and Thomas 2005). I find that there is a significant relationship between analyst_effort and reliability in the precise condition $(\mathrm{F}=4.32, \mathrm{p}=0.04)$. I also find that judge_forecast does not mediate the relationship between analyst_effort and reliability in the precise condition (indirect effect $=0.41,90 \%$ CI: -0.07 to 1.03 ). These results suggest that participants' reliability judgments are directly influenced by their perceptions of the effort put in by the analysts in making the forecasts. Further, their reliability judgments are not influenced by indirect effects via judge forecast (which would be indicative of systematic processing). Overall, these set of results are consistent with participants relying on heuristic processing rather than on systematic processing in the precise condition.
} 
(coefficient $=-2.33, \mathrm{p}<0.01$ ) and a positive effect of $j u d g e_{-}$forecast on reliability (coefficient $=0.76, \mathrm{p}<0.01$ ). The direct effect of forecast uncertainty on reliability is not significant (coefficient $=-0.30, \mathrm{p}=0.63$ ), indicating that the mediator fully explains the relationship between forecast uncertainty and reliability. Overall, there is a significant indirect effect of forecast uncertainty on reliability, via judge_forecast, with the $90 \%$ CI not including zero (effect=-1.76, 90\% CI: -2.83 to -0.82 ). These results suggest that the effect of forecast uncertainty on reliability is mediated by judge_forecast when analysts' EPS forecasts are round, consistent with H4b.

\section{(Insert Figure 3 here)}

\section{Additional analysis}

5.1. Examining investment judgments

Prior studies suggest that participants' judgments of forecast reliability will influence the extent to which these forecasts will be incorporated into their investment judgments (e.g. Abarbanell et al. 1995). Accordingly, I conducted analysis to examine the relationship between reliability and participants' investment judgments in my experiment. In my experiment, participants made investment judgments by rating their agreement of the extent that the company is a good investment. This rating was made on a fifteen-point scale, with 0 as the midpoint and -7 (+7) corresponding to "strongly disagree" ("strongly agree"). In addition, participants also provided their range estimates of the company's actual EPS (i.e. high and low estimates). I computed a composite measure of participants' investment judgments (investment) by obtaining the standardized scores of (i) participants' ratings of their agreement of the extent that the company is a good investment and (ii) the average of their high and low estimates of the company's actual EPS, and calculating the average of the two standardized scores. To the extent that investors rely more heavily on analysts' EPS 
forecasts in making investment judgments when they perceive those EPS forecasts to be more reliable, I am likely to also observe a significant association between reliability and investment. Consistent with this prediction, I find that reliability is significantly associated with investment $(\mathrm{t}=6.30, \mathrm{p}<0.01)$. This relationship is significant both in the precise $(\mathrm{t}=6.06$, $\mathrm{p}<0.01)$ and round $(\mathrm{t}=3.03, \mathrm{p}<0.01)$ conditions. Overall, these results suggest that participants' judgments of forecast reliability influences the extent to which these forecasts are used in forming investment judgments.

\subsection{Examining forecast magnitude}

In my experiment, participants in the round (precise) condition were provided with analyst EPS forecasts of $\$ 10.00$ ( $\$ 10.11)$. While this manipulation varied the precision of EPS forecasts, it also varied the magnitude of the forecasts, with the forecast in the precise condition being $\$ 0.11$ larger than the forecast in the round condition. This leaves open the possibility that the results in the main experiment are driven by differences in EPS forecast magnitude rather than by differences in forecast precision. To address this issue, I administered two additional experimental conditions (low_uncertainty/precise_small and high_uncertainty/precise_small). All aspects of the low_uncertainty/precise_small and high_uncertainty/precise_small conditions were identical to the low_uncertainty/precise and high_uncertainty/precise conditions respectively, except that analyst EPS forecasts of $\$ 9.89$ (rather than \$10.11) were provided in the two new conditions. This ensures that while participants in the precise conditions received precise EPS forecasts that were $\$ 0.11$ larger than participants in the round condition, participants in the precise_small condition received precise EPS forecasts that were $\$ 0.11$ smaller than participants in the round conditions. This two additional experimental conditions were administered at the same time as the other conditions in the main experiment. I recruited a total of 59 participants from AMT but 
excluded 15 participants who answered at least one attention check questions incorrectly, leaving 44 participants. $^{14}$

Panel A of Table 3 presents descriptive statistics for reliability. Reliability is no different in the low_uncertainty/precise (mean=3.23) and low_uncertainty/precise_small (mean $=2.57, \mathrm{t}=0.76, \mathrm{t}=0.45$ ) conditions. It is also no different in the high_uncertainty/precise (mean=2.83) and high_uncertainty/precise_small $($ mean $=1.91, \mathrm{t}=0.93, \mathrm{t}=0.36)$ conditions. These results suggest that participants' ratings of reliability are no different when precise EPS forecasts of higher magnitude (as in the precise condition) or lower magnitude (as in the precise_small condition) are presented across equivalent forecast uncertainty conditions. Consistent with H1 which states that when analysts issues precise EPS forecasts, investors' judgments of forecast reliability will not be influenced by forecast uncertainty, I find that reliability is not significantly different across the low_uncertainty/precise_small (mean=2.57) and high_uncertainty/precise_small $($ mean $=1.91, \mathrm{t}=0.64, \mathrm{p}=0.53)$ conditions. Further, to examine whether the overall pattern of reliability judgments correspond to $\mathrm{H} 1$ and $\mathrm{H} 2$, I also conducted a planned contrast test on reliability judgments in the precise_small and round conditions. Panel B of Table 3 presents the results of the planned contrast. The contrast test was marginally significant $(\mathrm{F}=2.60, \mathrm{p}=0.11)$, suggesting that reliability judgments in the precise_small relative to the round conditions are similar to equivalent judgments in the precise conditions. ${ }^{15}$ Overall, these results are consistent with participants' ratings of reliability being no different across the precise and precise_small conditions, suggesting that their judgments are not driven by differences in forecast magnitude.

\footnotetext{
${ }^{14}$ These 44 participants had a mean (standard deviation) age of 33.14 (26.68) years, a mean (standard deviation) work experience of 7.24 (10.35) years, and had taken a mean (standard deviation) of 2.12 (3.79) accounting/finance courses. About $67.6 \%$ of them had investing experience while $69.9 \%$ of them intended to make investments in the next twelve months.

15 The contrast codes were +1 in the two precise_small conditions, +1 in the low_uncertainty/round condition, and -3 in the high_uncertainty/round condition. The equivalent planned contrast test in the main experiment, presented in Panel $\mathrm{C}$ of Table 1 , is significant $(\mathrm{F}=7.03, \mathrm{t}=0.01)$.
} 


\section{Conclusion}

In this study, I conducted an experiment to examine the joint effects of forecast uncertainty and forecast precision on investor judgments of forecast reliability. I find that when precise analyst forecasts are presented, investor judgments of forecast reliability are not influenced by forecast uncertainty. Further, I find that investors' judgments of the overall conditions under which the forecasts were made are not influenced by forecast uncertainty, and that the relationship between forecast uncertainty and forecast reliability is not mediated by these investors' judgments of the overall conditions under which the forecasts were made when precise forecasts are presented. In contrast, I find that when round analyst forecasts are presented investor judgments of forecast reliability are greater when forecast uncertainty is low than when it is high. Further I find that investors' judgments of the overall conditions under which the forecasts were made are greater when forecast uncertainty is low than when it is high, and that the relationship between forecast uncertainty and forecast reliability is mediated by these investors' judgments of the overall conditions under which the forecasts were made when round forecasts are presented. In additional analysis, I find that investor judgments of forecast reliability are significantly associated with their investment judgments. I also rule out the possibility that my results are driven by differences in forecast magnitude rather than by differences in forecast precision across corresponding forecast precision conditions.

My study extends the literature on forecast precision and forecast uncertainty. My findings are important to both analysts and investors because I highlight how precise forecasts lead to a positive attribution-of-competence effect which forms the basis of heuristic judgments of forecast reliability while round forecasts do not lead to an equivalent negative 
attribution-of-competence effect. Consequently, investors rely on systematic processes, and carefully evaluate all relevant information including that relating to forecast uncertainty, in forming judgments. To the extent that both forecast precision and forecast uncertainty are relevant pieces of information in making judgments about analyst EPS forecast reliability (Hermann and Thomas 2005; Barron et al. 1998), my results would provide important insights into how investors process these pieces of information in forming their judgments.

One limitation of my study relates to its contextualized nature. In particular, I rely on the HSM to develop my theory, and highlight that more effortful systematic processing occurs when heuristic processing alone yields insufficient judgment confidence to breach the sufficiency threshold. More specifically, the sufficiency principle claims that systematic processing is dependent on the actual amount of confidence that exists in one's judgment that falls short of the desired amount of confidence, and that the gap between actual and desired confidence is experienced by a decision maker as a feeling that his/her judgment is insufficient (Bohner et al. 1995). Given that different groups of stakeholders who rely on analysts' forecasts have different motivations in doing so, their desired level of confidence in their judgments are likely to differ accordingly. Further, given that different users of analyst forecasts are likely to have different desired levels of confidence, their decision to rely on heuristic processes (and not engage in systematic processes) in forming their forecast reliability judgments is also likely to differ. This potentially limits the generalizability of my results, particularly those in the precise condition where participants are predicted to rely on heuristic processing in forming reliability judgments. My study also highlights possible areas of future research. While my study highlights forecast uncertainty as one contextual factor that influences investor judgments of forecast reliability (particularly when forecasts are round), future research could examine how other contextual factors might interact with forecast precision to influence investor judgments of forecast reliability. Further, in my 
experiment, I introduce round EPS forecasts that contain round numbers in both the ten-cent and cent digits (\$10.00) and precise EPS forecasts that contain precise numbers in both the ten-cent and cent digits (\$9.89 and \$10.11). Future studies could build on this to examine the effects different forms of rounding (e.g. lower levels of rounding and precision, where only the cent digit contains round or precise numbers) on investor judgments. 


\section{Appendix 1: Analyst report presented to participants}

$\underline{\text { Round EPS forecast and low forecast uncertainty }}$

\section{MORGAN FINANCIAL}

Equities Research Report

\section{GR Ocean, Inc.}

\section{Introducing FY2017 EPS Forecast of \$10.00; High Certainty in Forecast}

Introducing FY 2017 EPS forecast of \$10.00 per share: In 2016, GR Ocean announced the signing of a major contract to manufacture 2 million tablets per year for Togo, Inc., a leading global consumer electronics brand. We expect that this contract will significantly increase GR Ocean's market share in the North America region and contribute to earnings from FY2017.

The certainty of our EPS forecast is high because GR Ocean was able to provide details about the timing of the execution of the contract in its most recent earnings call.

\section{Round EPS forecast/ high forecast uncertainty}

\section{MORGAN FINANCIAL}

Equities Research Report

\section{GR Ocean, Inc.}

Introducing FY2017 EPS Forecast of \$10.00; Low Certainty in Forecast

Introducing FY 2017 EPS forecast of \$10.00 per share: In 2016, GR Ocean announced the signing of a major contract to manufacture 2 million tablets per year for Togo, Inc., a leading global consumer electronics brand. We expect that this contract will significantly increase GR Ocean's market share in the North America region and contribute to earnings from FY2017.

The certainty of our EPS forecast is low because GR Ocean was not able to provide details about the timing of the execution of the contract in its most recent earnings call. 


\section{Precise EPS forecast and low forecast uncertainty}

\section{MORGAN FINANCIAL}

Equities Research Report

GR Ocean, Inc.

Introducing FY2017 EPS Forecast of \$10.11; High Certainty in Forecast

Introducing FY 2017 EPS forecast of \$10.11 per share: In 2016, GR Ocean announced the signing of a major contract to manufacture 2 million tablets per year for Togo, Inc., a leading global consumer electronics brand. We expect that this contract will significantly increase GR Ocean's market share in the North America region and contribute to earnings from FY2017.

The certainty of our EPS forecast is high because GR Ocean was able to provide details about the timing of the execution of the contract in its most recent earnings call.

\section{Precise EPS forecast/ high forecast uncertainty}

\section{MORGAN FINANCIAL}

Equities Research Report

\section{GR Ocean, Inc.}

\section{Introducing FY2017 EPS Forecast of \$10.11; Low Certainty in Forecast}

Introducing FY 2017 EPS forecast of \$10.11 per share: In 2016, GR Ocean announced the signing of a major contract to manufacture 2 million tablets per year for Togo, Inc., a leading global consumer electronics brand. We expect that this contract will significantly increase GR Ocean's market share in the North America region and contribute to earnings from FY2017.

The certainty of our EPS forecast is low because GR Ocean was not able to provide details about the timing of the execution of the contract in its most recent earnings call. 


\section{References}

Abarbanell, J. S., Lanen, W. N., \& Verrecchia, R. E. (1995). Analysts' forecasts as proxies for investor beliefs in empirical research. Journal of Accounting and Economics, 20 (1), 31-60.

Bamber L. S., Hui, K. W., \& Yeung, P. E. (2010). Managers' EPS forecasts: Nickeling and diming the market? The Accounting Review, 85 (1), 63-95.

Barron, O. E., Kim, O., Lim, S. C., \& Stevens, D. E. (1998). Using analysts’ forecasts to measure properties of analysts' information environment. The Accounting Review, 73 (4), 421-433.

Bohner, G., Moskowitz, G. B., \& Chaiken, S. (1995). The interplay of heuristic and systematic processing of social information. European Review of Social Psychology, 6 (1), 33-68.

Buckless, F. A., \& Ravenscroft, S. P. (1990). Contrast coding: A refinement of ANOVA in behavioral analysis. The Accounting Review, 65 (4), 933-945.

Chaiken, S. (1980). Heuristic versus systematic information processing and the use of source versus message cues in persuasion. Journal of Personality and Social Psychology, 39, $752-766$.

Chaiken, S. (1987). The heuristic model of persuasion. In M. P. Zanna, J. M. Olsen, \& C. P. Herman (Eds.), Social influence: The Ontario symposium (Vol. 5, pp. 3-39). Hillsdale, N. J.: Lawrence Erlbaum Associates, Inc.

Chaiken, S., \& Maheswaran, D. (1994). Heuristic processing can bias systematic processing: Effects of source credibility, argument ambiguity, and task importance on attitude judgement. Journal of Personality and Social Psychology, 66, 460-473.

Chaiken, S., Giner-Sorolla, R., \& Chen, S. (1996). Beyond accuracy: Defense and impression motives in heuristic and systematic information processing. In P. M. Gollwitzer \& J. 
A. Bargh (Eds.), The psychology of action: Linking cognition and motivation to behaviour (pp. 553-578). New York: Guilford.

Chaiken, S., Liberman, A., \& Eagly, A. H. (1989). Heuristic and systematic processing within and beyond the persuasion context. In J. S. Uleman \& J. A. Bargh (Eds.), Unintended thought (pp. 212-252). New York: Guilford.

Chen, S., Duckworth, K., \& Chaiken, S. (1999). Motivated heuristic and systematic processing. Psychological Inquiry, 10 (1), 44-49.

Clement, M, Frankel, R. \& Miller, J. (2003). Confirming management earnings forecasts, earnings uncertainty, and stock returns. Journal of Accounting Research, 41 (4), 653679.

Dechow, P., \& You., H. (2012). Analysts' motives for rounding EPS forecasts. The Accounting Review, 87 (6), 1939-1966.

Hauser, D. J., \& Schwarz, N. (2016). Attentive Turkers: Mturk participants perform better on online attention checks than do subject pool participants. Behavior Research Methods, $48(1), 400-407$.

Hayes, A. F. (2012). PROCESS: A versatile computational tool for observed variable mediation, moderation, and conditional process modeling. White paper. Retrieved from: http://www.afhayes.com/public/process2012.pdf

Hayward, M., \& Fitza, M. (2017). Pseudo-precision? Precise forecasts and impression management in managerial earnings forecasts. Academy of Management Journal, 60 (3), 1094-1116.

Herrmann, D., \& Thomas, W. (2005). Rounding of analyst forecasts. The Accounting Review, $80(3), 805-823$.

Janiszewski, C. \& Uy, D. (2008). Precision of the anchor influences the amount of adjustment. Psychological Science, 19 (2), 121-127. 
Jerez-Fernandez, A., Angulo, A. N. \& Oppenheimer, D. M. (2014). Show me the numbers: Precision as a cue to others' confidence. Psychological Science, 25, 633-635.

Johnson, T. C. (2004) Forecast dispersion and the cross section of expected returns. Journal of Finance, 59, 1957-1978.

Koonce, L., Miller, J. S., \& Winchel, J. (2015). The effects of norms on investor reactions to derivative use. Contemporary Accounting Research, 32 (4), 1529-1554.

Krische, S. D. (2015). The impact of individual investors' financial literacy on assessments of conflicts of interest. Working paper, American University.

Libby, R., Bloomfield, R., \& Nelson, M. (2002). Experimental research in financial accounting. Accounting, Organizations, and Society, 27, 775-810.

Loibl, C., \& Hira, T. K. (2009). Investor information search. Journal of Economic Psychology, 30 (1), 24-41.

Loschelder, D., Friese, M., Schaerer, M, \& Galinsky, A. (2016). The too-much-precision effect: When and why precise anchors backfire with experts. Psychological Science, $27,1573-1587$

Maheswaran, D., \& Chaiken, S. (1991). Promoting systematic processing in low-motivation settings: Effect of incongruent information on processing and judgement. Journal of Personality and Social Psychology, 61, 13-25.

Mason, M., Lee, A., Wiley, Elizabeth, \& Ames, D. (2013). Precise offers are potent anchors: Conciliatory counteroffers and attributions of knowledge in negotiations. Journal of Experimental Social Psychology, 49 (4), 759-763.

Mittendorf, B., \& Zhang, Y. (2005). The role of biased earnings guidance in creating a healthy tension between managers and analysts. The Accounting Review, 80, 4, 11931209. 
Paolacci, G., Chandler, J., \& Ipeirotis, P. (2010). Running experiments on Amazon Mechanical Turk. Judgment and Decision Making, 5 (5), 411-419.

Preacher, K. J., \& Hayes, A. (2008). Asymptotic and resampling strategies for assessing and comparing indirect effects in multiple mediator models. Behavior Research Methods, $40(3), 879-891$.

Rennekamp, K. (2012). Processing fluency and investors' reactions to disclosure readability. Journal of Accounting Research, 50 (5), 1319-1354.

Roberts, J., \& Brewer, D. (2001). Measures and tests of heaping in discrete quantitative distributions. Journal of Applied Statistics, 28, 887-896.

Rupar, K. (2017). Significance of forecast precision: The importance of investors' expectations. Contemporary Accounting Research, 34 (2), 849-870.

Sheng, X. \& Thevenot, M. (2012). A new measure of earnings forecast uncertainty. Journal of Accounting and Economics, 53 (1), 21-33.

Smith, A., Dandurand, M, \& Turnure, C. (2012). American electric power. J. P. Morgan North America Equity Research.

Tsujino, N. (2012). P\&C insurance industry. J. P. Morgan Japan Equity Research.

Ureta, M. (1992). The importance of lifetime jobs in the U.S. economy, revisited. American Economic Review, 82, 322-335.

Yeung, P. E. (2009). Uncertainty and expectation revisions after earnings announcements. Contemporary Accounting Research, 26, 273-301.

Zhang, F. X. (2006). Information uncertainty and stock returns. Journal of Finance, 61 (1), 105-137. 


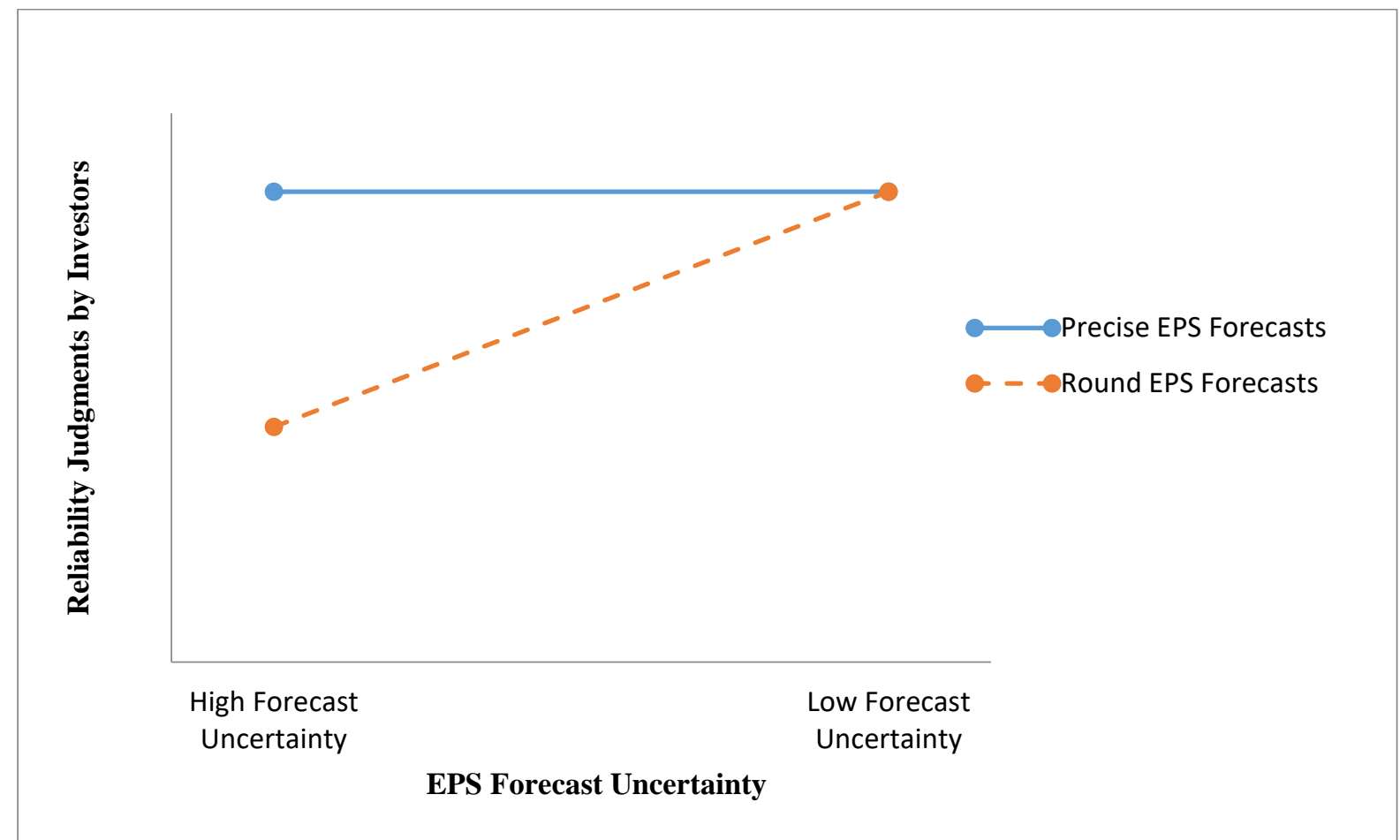

Fig. 1. Predicted forecast reliability judgments by investors. This figure presents predicted mean forecast reliability judgments of investors. Lines represent predicted mean forecast reliability judgments of analysts' EPS forecasts by investors when forecast uncertainty is high and when it is low. Higher (lower) levels of reliability judgment indicate that investors rate the forecast as being more (less) reliable. 


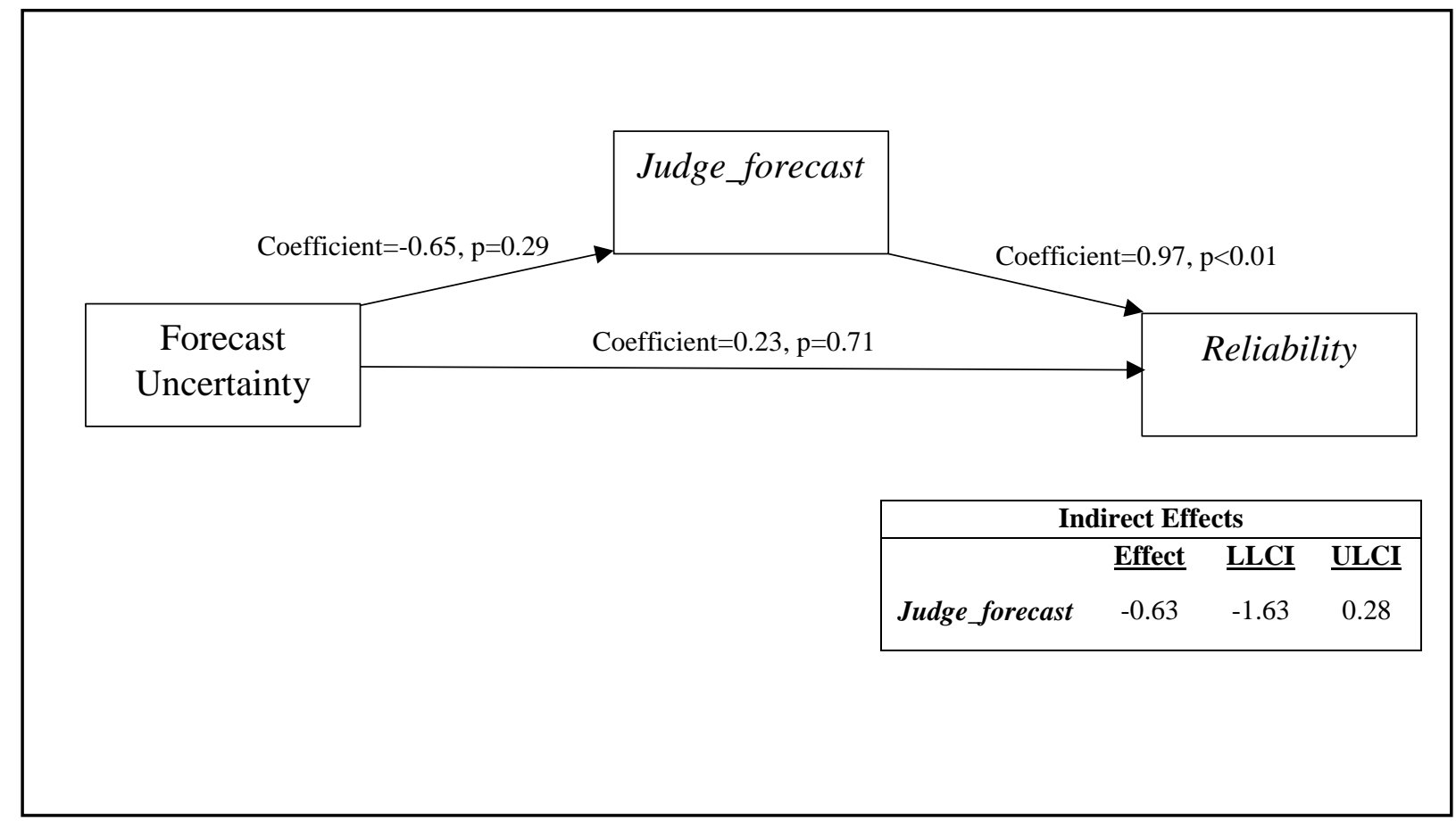

Fig 2. Mediation analysis for participants in the precise condition. This figure illustrates the mediation analysis when participants are presented with precise EPS forecasts, with forecast uncertainty as the independent variable, judge_forecast as the mediator, and reliability as the dependent variable. I used the Hayes PROCESS macro (Hayes 2012) to estimate the path coefficients through 10,000 bootstrapped samples with a 90\% confidence interval. Judge_forecast represents participants' judgments of the overall conditions under which the forecasts were made. It is computed by taking the average of participants' ratings of the extent that they agreed that the analysts who wrote the analyst report are informed about the company and had sufficient information to provide the EPS forecast. Reliability represents participants' ratings of the extent that they agreed that the analyst EPS forecast provided is reliable. Participants rated their agreement on 15-point scales ($7=$ Strongly disagree; $7=$ Strongly agree). 


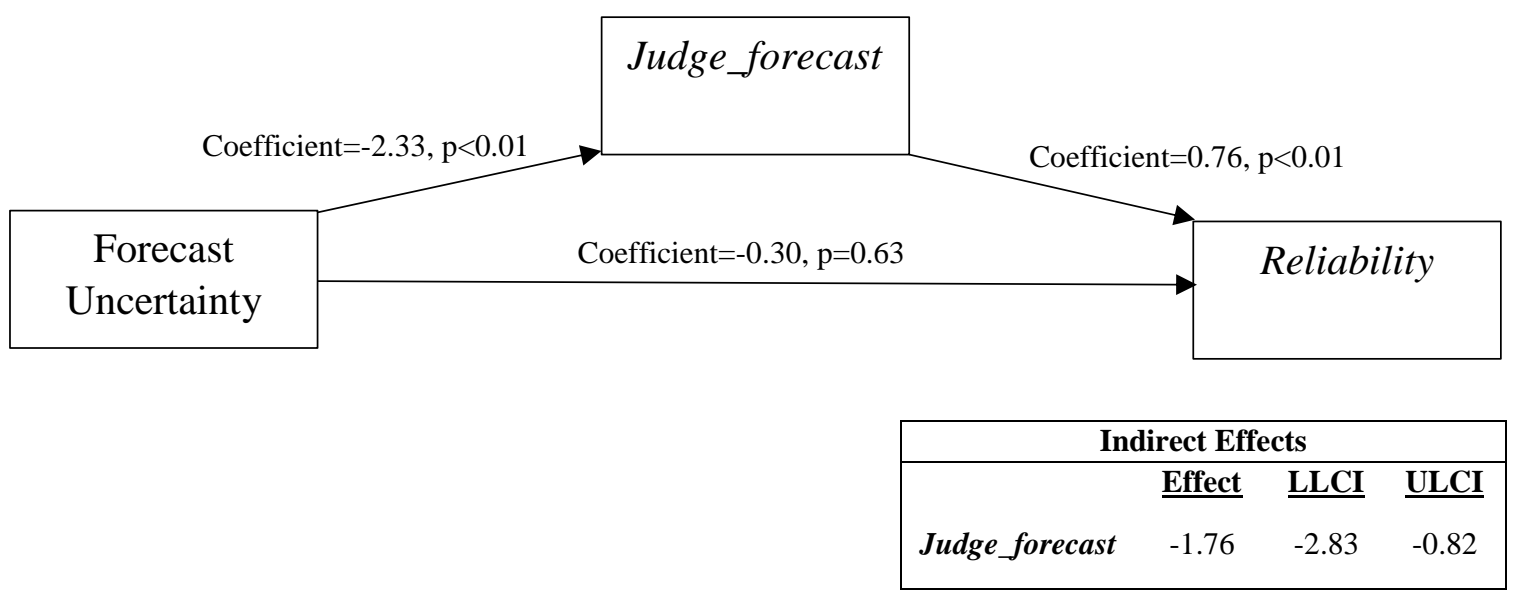

Fig 3. Mediation analysis for participants in the round condition. This figure illustrates the mediation analysis when participants are presented with round EPS forecasts, with forecast uncertainty as the independent variable, judge_forecast as the mediator, and reliability as the dependent variable. I used the Hayes PROCESS macro (Hayes 2012) to estimate the path coefficients through 10,000 bootstrapped samples with a $90 \%$ confidence interval. Judge_forecast represents participants' judgments of the overall conditions under which the forecasts were made. It is computed by taking the average of participants' ratings of the extent that they agreed that the analysts who wrote the analyst report are informed about the company and had sufficient information to provide the EPS forecast. Reliability represents participants' ratings of the extent that they agreed that the analyst EPS forecast provided is reliable. Participants rated their agreement on 15-point scales ($7=$ Strongly disagree; $7=$ Strongly agree). 
Table 1 Participants' judgments analysts' EPS forecast reliability (reliability)

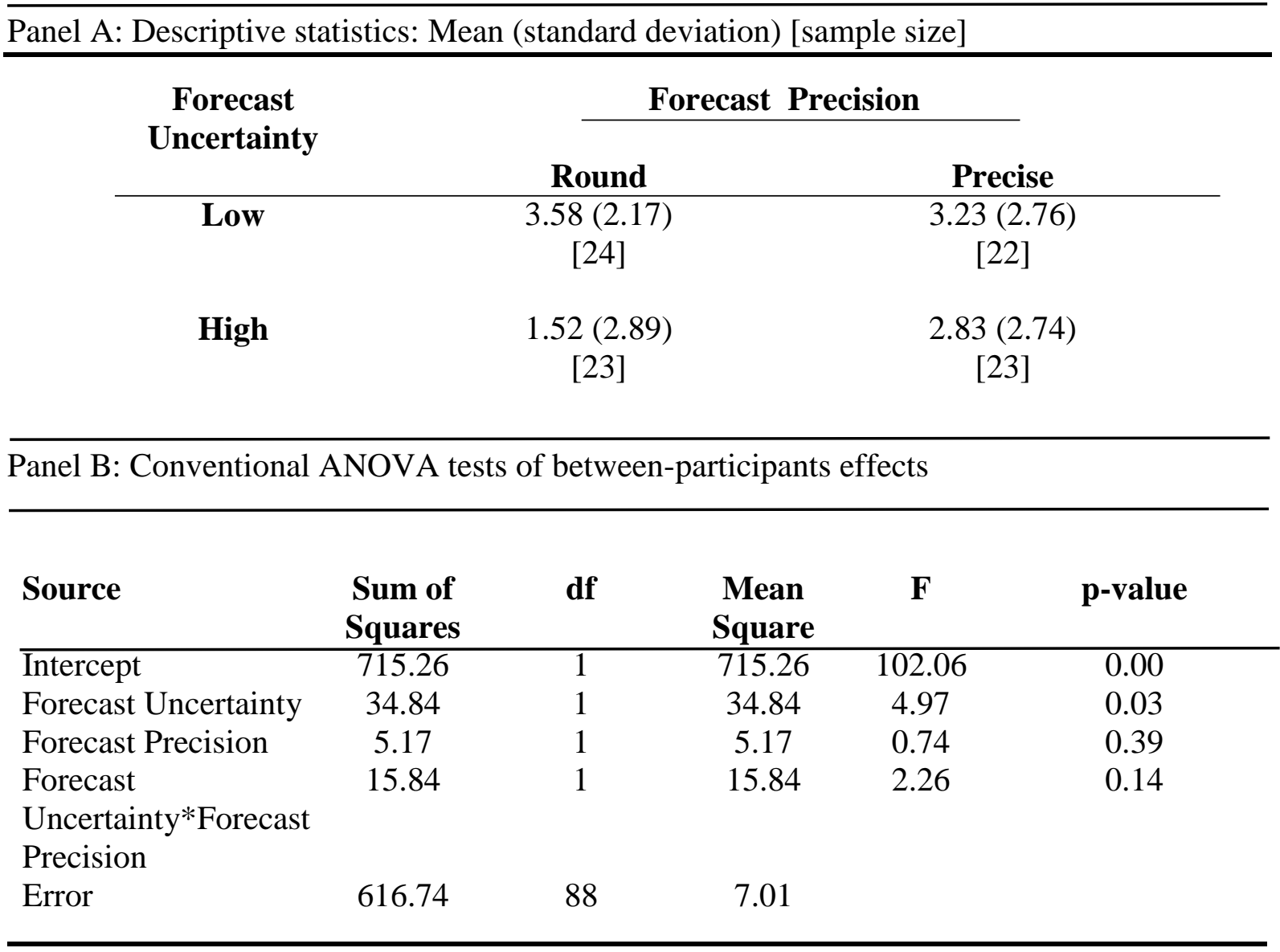


Table 1 (Continued) Participants' judgments analysts' EPS forecast reliability (reliability)

Panel C: Planned contrast testing for $\mathrm{H} 1$ and $\mathrm{H} 1 \mathrm{~b}$

H1a and H1b: low_uncertainty/round + low_uncertainty/precise + high_uncertainty/precise $-3 \mathrm{x}$ high_uncertainty/round $=0$

\begin{tabular}{|c|c|c|c|c|c|}
\hline & $\begin{array}{l}\text { Sum of } \\
\text { Squares }\end{array}$ & df & $\begin{array}{c}\text { Mean } \\
\text { Square }\end{array}$ & $\mathbf{F}$ & p-value \\
\hline Contrast: $(+1,+1,+1,-3)$ & 49.28 & 1 & 49.28 & 7.03 & 0.01 \\
\hline \multicolumn{6}{|c|}{ Panel D: Follow up simple effects tests } \\
\hline Simple Effects & $\begin{array}{l}\text { Sum of } \\
\text { Squares }\end{array}$ & df & $\begin{array}{c}\text { Mean } \\
\text { Square }\end{array}$ & $\mathbf{F}$ & p-value \\
\hline $\begin{array}{l}\text { Effect of forecast } \\
\text { uncertainty when } \\
\text { analysts' EPS } \\
\text { forecasts are round }\end{array}$ & 49.92 & 1 & 49.92 & 7.70 & 0.01 \\
\hline $\begin{array}{l}\text { Effect of forecast } \\
\text { uncertainty when } \\
\text { analysts' EPS } \\
\text { forecasts are precise }\end{array}$ & 1.81 & 1 & 1.81 & 0.24 & 0.63 \\
\hline
\end{tabular}

Table 1 presents statistical analysis related to participants' judgments of analysts' EPS forecast reliability. Panel A presents the descriptive statistics for reliability. Reliability represents participants' ratings of the extent that they agreed that the analyst EPS forecast provided is reliable. Participants rated their agreement on a 15-point scale ( $7=$ Strongly disagree; $7=$ Strongly agree). Panel B presents the conventional analysis of variance (ANOVA). Panel C presents main and interaction planned contrasts. Panel D presents follow-up simple main effects tests. 
Table 2 Participants' comprehensive judgments of EPS forecast characteristics (judge_forecast)

Panel A: Descriptive statistics: Mean (standard deviation) [sample size]

\begin{tabular}{ccc} 
Forecast & \multicolumn{2}{c}{ Forecast Precision } \\
\cline { 2 - 3 } Uncertainty & Round & Precise \\
\hline Low & $3.83(2.04)$ & $3.84(1.84)$ \\
& {$[24]$} & {$[22]$} \\
High & $1.50(2.60)$ & $3.20(2.16)$ \\
& {$[23]$} & {$[23]$} \\
\hline
\end{tabular}

Panel B: Conventional ANOVA tests of between-participants effects

\begin{tabular}{lccccc}
\hline Simple Effects & $\begin{array}{c}\text { Sum of } \\
\text { Squares }\end{array}$ & df & $\begin{array}{c}\text { Mean } \\
\text { Square }\end{array}$ & F & p-value \\
\hline $\begin{array}{l}\text { Effect of forecast } \\
\text { uncertainty when } \\
\text { analysts' EPS } \\
\text { forecasts are round }\end{array}$ & 63.94 & 1 & 63.94 & 11.80 & 0.00 \\
$\begin{array}{l}\text { Effect of forecast } \\
\text { uncertainty when } \\
\text { analysts' EPS } \\
\text { forecasts are precise }\end{array}$ & 4.68 & 1 & 4.68 & 1.16 & 0.29 \\
& & & & & \\
\hline
\end{tabular}

\footnotetext{
${ }^{\mathrm{a}}$ Table 2 presents statistical analysis related to participants' comprehensive judgments of analysts' EPS forecast characteristics (judge_forecast). Panel A presents the descriptive statistics for judge_forecast. Judge_forecast represents participants' comprehensive judgments of analysts' EPS forecasts. It is computed by taking the average of participants' ratings of the extent that they agreed that the analysts who wrote the analyst report are informed about the company and had sufficient information to provide the EPS forecast. Participants rated their agreement on a 15-point scale (-7=Strongly disagree; $7=$ Strongly agree). Panel B presents follow-up simple main effects tests.
} 
Table 3 Participants' judgments analysts' EPS forecast reliability (reliability)

\begin{tabular}{cccc}
\hline Panel A: Descriptive statistics: Mean (standard deviation) [sample size] & \\
\cline { 1 - 2 } Forecast & & Forecast Precision & \\
\cline { 3 - 4 } Uncertainty & Round & Precise & Precise_Small \\
\hline Low & $3.58(2.17)$ & $3.23(2.76)$ & $2.57(2.91)$ \\
& {$[24]$} & {$[22]$} & {$[21]$} \\
High & $1.52(2.89)$ & $2.83(2.74)$ & $1.91(3.83)$ \\
& {$[23]$} & {$[23]$} & {$[23]$} \\
& & & \\
\hline Panel B: Planned contrast testing for H1 and H1b & & \\
\hline
\end{tabular}

H1a and H1b: low_uncertainty/round + low_uncertainty/precise_small + high_uncertainty/precise_small $-3 \mathrm{x}$ high_uncertainty/round $=0$

\begin{tabular}{lccccc}
\hline & $\begin{array}{c}\text { Sum of } \\
\text { Squares }\end{array}$ & df & $\begin{array}{c}\text { Mean } \\
\text { Square }\end{array}$ & F & p-value \\
\hline Contrast: $(+1,+1,+1,-3)$ & 23.41 & 1 & 23.41 & 2.60 & 0.11
\end{tabular}

Table 3 presents statistical analysis related to participants' judgments of analysts' EPS forecast reliability. Panel A presents the descriptive statistics for reliability. Reliability represents participants' ratings of the extent that they agreed that the analyst EPS forecast provided is reliable. Participants rated their agreement on a 15 -point scale $(-7=$ Strongly disagree; $7=$ Strongly agree). Panel B presents main and interaction planned contrasts. 